\title{
The Relationship between Vehicle Yaw Acceleration Response and Steering Velocity for Steering Control
}

\author{
M.J. Thoresson; T.R. Botha; P.S. Els \\ Department of Mechanical and Aeronautical Engineering, University of Pretoria, Pretoria 0002, South \\ Africa
}

\begin{abstract}
This paper proposes a novel concept for the modelling of a vehicle steering driver model for path following. The proposed steering driver reformulates and applies the Magic Formula, used for tyre modelling, to the vehicle's yaw acceleration vs. steering velocity response as a function of vehicle speed.

The path-following driver model was developed for use in gradient-based mathematical optimisation of vehicle suspension characteristics for handling. Successful application of gradient-based optimisation depends on the availability of good gradient information. This requires a robust driver model that can ensure completion of the required handling manoeuvre, even when the vehicle handling is poor.

The steering driver is applied to a non-linear full vehicle model of a Sports Utility Vehicle, performing a severe double lane change manoeuvre. Simulation results show excellent correlation with test results. The proposed driver model is robust and well suited to gradient-based optimisation of vehicle handling.
\end{abstract}

Keywords: driver model, Magic Formula, steering response, tyre characteristics, handling, mathematical optimisation.

\section{Introduction}

The use of lateral path following driver models for the simulation of closed loop vehicle handling manoeuvres is vital. However, great difficulty is often experienced in determining the gain parameters for a stable driver at all realistic vehicle speeds, and vehicle parameters.

The primary reason for requiring a driver model in the present study is for the optimisation of an off-road vehicle's suspension system. The suspension characteristics are to be optimised for handling, while performing the closed loop ISO 3888-1 (International Organisation for Standardisation, 2004) severe double lane change manoeuvre. The driver model thus has to be robust for various suspension setups, and perform only one simulation to return the objective function value. Therefore steering controllers with learning capability will not be considered, as the suspension could be vastly different from one simulation to the next. Only lateral path following is considered in this preliminary research, as the double lane change manoeuvre is normally performed at a constant vehicle speed. Furthermore the main purpose of the driver model is to enable successful completion of the handling manoeuvre, so that good gradient 
information can be determined, especially when the suspension settings are far from the optimum settings for handling. Accurate representations of real human driver behaviour under these conditions are less important than the successful completion of the manoeuvre.

The current research is concerned with the development of a controllable suspension system for Sports Utility Vehicles (SUV's). The suspension system has to be modelled, and the handling dynamics simulated, for widely varying suspension settings. The vehicle in question has a comparatively soft suspension, coupled to a high centre of gravity, resulting in large suspension deflections when performing the double lane change manoeuvre. This large suspension deflection results in highly unstable vehicle behaviour, eliminating the use of driver models suited to vehicles with minimal suspension deflection. Steady state rollover calculations also show that the vehicle will roll over before it will slide.

A robust driver model is difficult to achieve, especially when suspension spring and damper characteristics are allowed to vary over a wide range. The determination of driver model parameters become especially complex when accurate, non-linear full vehicle models, with large suspension travel, are to be controlled in proximity to the handling limits of the vehicle.

This research proposes a novel lateral path-following driver model based on the relationship between vehicle yaw response and non-linear tyre characteristics. The nonlinearity of the tyre characteristics is replicated for the steering model's parameters. The non-linear response of the vehicle is captured by fitting the Magic Formula (frequently used for tyre lateral force vs. slip angle modelling) to the vehicle's yaw acceleration vs. steering velocity for different vehicle speeds.

Previous research into lateral vehicle model drivers is now discussed, followed by the mathematical vehicle model. The characterization of the vehicle's dynamics, with the Magic Formula driver model, and the implementation thereof completes the paper.

An extensive overview of driver models for vehicle dynamics applications is given by Plöchl and Edelmann (2007). Many different driver models have been proposed, most of which have specific applications and are difficult to generalise for all requirements.

Snider (2009) evaluated various driver models in CarSim (2011). The driver models ranged from simple kinematic and geometric models, used by various autonomous vehicles (Thrun et al., 2006 and Urmson et al., 2008), to more complex dynamic models based on optimal control theory (Tewari, 2002). Snider (2009) concluded that the driver models can be tuned to suit a specific range of conditions. With most exhibiting a compromise between low speed performance and high speed stability.

Sharp, Casanova and Symonds (2000) implement a linear, multiple preview point controller, with steering saturation limits mimicking tyre saturation, for vehicle tracking. The vehicle model used is a 5-degree-of-freedom (dof) model, with non-linear Magic Formula tyre characteristics, but no suspension deflection. This model is successfully 
applied to a Formula One vehicle performing a lane change manoeuvre. Gordon, Best and Dixon (2002) make use of a novel method, based on convergent vector fields, to control the vehicle along desired routes. The vehicle model is a 3-dof vehicle, with nonlinear Magic Formula tyre characteristics, but with no suspension deflection included. The driver model is successfully applied to lane change manoeuvres. The primary similarity between these methods is that vehicle models with no suspension deflection were used.

Prokop (2001) implements a PID (Proportional Integral Derivative) prediction model for tracking control of a bicycle model vehicle. The driver model makes use of a driver plant model that is representative of the actual vehicle. The driver plant increases with complexity to perform the required dynamic manoeuvre, from a point mass to a two track model with elastokinematic suspension. This model is then optimised with the SQP (Sequential Quadratic Programming) optimisation algorithm for each time step. This approach, however, becomes computationally expensive, when optimisation of the vehicle's handling is to be considered.

A typical simple linearised single point path following driver model is discussed by Genta (1997). This type of driver model is frequently used in the simulation of vehicle handling.

For the current research several driver model approaches were implemented, but with limited success. Due to the unsuccessful implementation of these driver models for steering control, it was decided to characterize the whole vehicle system, using step steer, and ramp steer inputs, and observe various vehicle parameters. This lead to the discovery that the relationship between vehicle yaw acceleration vs. steering rate for various vehicle speeds appeared very similar to the side force vs. slip angle characteristics of the tyres. With this discovery it was decided to implement the proposed novel driver model, with the gain factor modelled with the Pacejka Magic Formula, normally used for tyre data.

\section{Mathematical Vehicle Model}

For the simulation performed in this study, a Land Rover Defender 110 is modelled in MSC.ADAMS View with standard suspension settings, as a baseline. The non-linear MSC.ADAMS Pacejka 89 tyre model (Bakker, Pacejka and Linder, 1989) is fitted to measured tyre data, and used within the model. The tyre's vertical dynamics and load dependent lateral dynamics are considered in this model. The longitudinal dynamic behaviour of the tyres and vehicle is not considered because the vehicle is driven at constant speed. The vehicle body is modelled as two rigid bodies connected along the roll axis at the chassis height, by a revolute joint and a torsional spring, in order to better capture the vehicle dynamics due to body torsion in roll. The anti-roll bar is modelled as a torsional spring between the two rear trailing arms to be representative of the actual anti-roll bar's effect. The bump and rebound stops are modelled with non-linear splines, as force elements between the axles and vehicle body. The suspension bushings are modelled as kinematic joints with torsional spring characteristics that are representative of the actual vehicle's suspension joint characteristics, in an effort to speed up the 
solution time, and help decrease numerical noise. The baseline vehicle's springs and dampers are modelled with experimentally determined non-linear splines. The vehicle's centre of gravity (cg) height and moments of inertia were also measured by Uys et al. (2005) and used within the model. Provision is made to vary the spring and damper characteristics over a wide range, for optimisation purposes. Figure 1 indicates the kinematic modelling of the rear and front suspensions. The complete model consists of 15 unconstrained degrees of freedom, 16 moving parts, 6 spherical joints, 8 revolute joints, 7 Hooke's joints, and one motion defined by the steering driver. The unconstrained degrees of freedom are indicated in table 1 .

Table 1 - MSC.ADAMS vehicle model's unconstrained degrees of freedom

\begin{tabular}{|c|c|c|}
\hline Body & Degrees of Freedom & Associated Motions \\
\hline $\begin{array}{c}\text { Vehicle Body } \\
(2 \text { rigid bodies })\end{array}$ & 7 & $\begin{array}{c}\text { body torsion } \\
\text { longitudinal, lateral, vertical } \\
\text { roll, pitch, yaw }\end{array}$ \\
\hline Front Axle & 2 & roll, vertical \\
\hline Rear Axle & 2 & roll, vertical \\
\hline Wheels & $4 \times 1$ & rotation \\
\hline
\end{tabular}

The speed control is modelled as a variable force attached to the body at wheel centre height. The magnitude of this force depends on the difference between the instantaneous speed and desired speed. Because the vehicle is four-wheel drive with open differentials, the vertical tyre force is measured at all tyres. If any tyre looses contact with the ground, the driving force to the vehicle is removed until all wheels are again in contact with the ground. This MSC.ADAMS model is then linked to the Simulink based driver model that returns as outputs the desired vehicle speed and steering angle, calculated using the vehicle's dynamic response.

The vehicle model is validated against measured test data for the double lane change manoeuvre at an entry speed of $65 \mathrm{~km} / \mathrm{h}$, where the steering input, as measured on the vehicle, is used to steer the simulation model. The results for the comparison between the MSC.ADAMS model and the measured results are presented in Figure 2, with excellent correlation achieved.

\section{Driver Model Description}

To investigate the relationship between vehicle response and steering inputs, simulations were performed for various constant steering input rates, at various vehicle speeds with the vehicle's baseline suspension system. The results of some of these simulations are displayed in Figure 3. The plots indicate that the yaw acceleration attains a constant value for a significant part of the duration of the simulation, for each specific steer rate and vehicle speed, for almost all steer rates at low speeds and for low steer rates at high speeds. It can also be noted that the response becomes larger as vehicle speed increases for the same steer rate. This increase in sensitivity is well known with modern vehicles equipped with active steering systems which reduce the steer ratio to improve steering stability at high vehicle speeds, such as BMW's active steering system Qinchao et al (2011). As a result of the increase in sensitivity, lower steer rates are required at higher 
speeds to generate the same yaw acceleration response. Thus, the use of lower steer rates at higher speeds ensures that the yaw acceleration response still obtains a constant value for a significant part of the input duration. These constant values of the responses suddenly reduce towards the end of the test. This sudden reduction is most likely due to the tyre reaching its saturation level.

Since both the steer rate and vehicle speed would influence the time to reach tyre saturation, the yaw acceleration was therefore plotted against lateral acceleration rather than time. The lateral acceleration also gives a measure of the level of tyre saturation. Figure 4 shows the yaw acceleration vs. lateral acceleration as a function of steer rate for different vehicle speeds. The figure better illustrates the near constant response obtained by the yaw acceleration. The response stays fairly constant up to very high lateral accelerations after which a sudden drop occurs (indicating that the tyre force is saturating).

Reymond et al. (2001), as well as Hugemann and Nickel (2002), showed that normal drivers typically reached higher lateral accelerations as vehicle speeds increased. This increase was however only up to a certain speed. After exceeding this speed they tended to reach lower lateral accelerations with increasing speed to increase the safety margin available to them. In their tests conducted during normal driving the lateral acceleration seldomly exceeded $6 \mathrm{~m} / \mathrm{s}^{2}$. Thus, the normal operating lateral accelerations of a vehicle can be considered to be below $6 \mathrm{~m} / \mathrm{s}^{2}$. If it is considered that the yaw acceleration response remains fairly constant below lateral acceleration of $6 \mathrm{~m} / \mathrm{s}^{2}$, it can be said that the yaw acceleration obtains a steady state response during normal operating conditions for a specific vehicle speed and steer rate.

It is thus possible to obtain the steady state yaw acceleration response as a function of steer rate and vehicle speed. The steady state yaw acceleration vs. steer rate curve, obtained from the results indicated in Figure 3 and 4 are shown in Figure 5. This trend is very similar to the tyre's lateral force vs. slip angle at various vertical loads as indicated in Figure 6. At low speeds the characteristic is linear but as the vehicle speed increases, the characteristic becomes more non-linear as the non-linearity of the tyres comes into play. Because of this trend it was postulated that the vehicle could be controlled by comparing the actual yaw acceleration to the desired yaw acceleration, and adjusting the steering input rate.

From kinematic principles it is known that, for a rigid body undergoing motion in a plane (see Figure 7), the rotational angle as a function of time is dependant on: the current rotational angle, $\psi_{a}$, the current rotational velocity, $\dot{\psi}_{a}$, the rotational acceleration, $\ddot{\psi}$, and the time step, $\tau$, over which the rotational acceleration is assumed constant. If the rotational acceleration is not constant, but sufficiently small time steps $\tau$ are considered, the predicted rotational angle $\psi_{d}$ will be sufficiently well approximated. The predicted rotational angle can therefore be determined as follows: 
$\psi_{d}=\psi_{a}+\dot{\psi}_{a} \tau+\frac{1}{2} \ddot{\psi} \tau^{2}$

The yaw acceleration $\ddot{\psi}$ needed to obtain the desired yaw angle at time $(t+\tau)$ is calculated from equation (1) as follows:

$\ddot{\psi}=2 \frac{\psi_{d}-\psi_{a}-\dot{\psi}_{a} \tau}{\tau^{2}}$

While most driver models only make use of the vehicle's yaw angle for control, this formulation uses the vehicle's yaw angle and yaw rate to better approximate the required steering input. The inclusion of the yaw rate in the formulation improves the robustness of the driver model.

The vehicle's steady state yaw acceleration, $\ddot{\psi}$, with respect to different steering rates, $\dot{\delta}$, was determined with the simulation model for a number of constant vehicle speeds, $\dot{x}$, as presented in Figure 5. The steady state yaw acceleration reached during every simulation was then used to generate the figure. When comparing Figure 5 to the vehicle's lateral tyre characteristics, presented in Figure 6, it appears reasonable that the Magic Formula could also be fitted to the steering response data. Therefore the reformulated Magic Formula, discussed below, is fitted to this data, and returns the required steering rate $\dot{\delta}$, which is defined as:

$\dot{\delta}=f(\ddot{\psi}, \dot{x})$

As output, the driver model provides the required steering rate $\dot{\delta}$, which is then integrated for the time step $\Delta t$ to give the required steering angle $\delta$.

\section{Magic Formula Fits}

The Magic Formula was proposed by Bakker, Pacejka and Linder (1989) to describe the tyre's handling characteristics in one formula. In this research the Magic Formula will be discussed in terms of the tyre's lateral force vs. slip angle relationship, which directly affects the vehicle's handling and steering response. The Magic Formula is defined as:

$y(x)=D \sin (C \arctan \{B x-E(B x-\arctan (B x))\})$

$Y(X)=y(x)+S_{v}$

$x=X+S_{h}$

The terms are defined as:

$Y(X)$ tyre lateral force $F_{y}$

$X$ tyre slip angle $\alpha$

$B$ stiffness factor 
$C$ shape factor

$D$ peak factor

$E$ curvature factor

$S_{h}$ horizontal shift

$S_{v}$ vertical shift

These terms are dependent on the vertical tyre load, $F_{z}$, and camber angle, $\gamma$. The Magic Formula can now be fitted to the steady state yaw acceleration vs. steering rate for different vehicle speeds as indicated in Figure 7, with the parameters redefined as:

vertical tyre load $F_{z}$ is equivalent to vehicle speed $\dot{x}$

tyre slip angle $\alpha$ is equivalent to steering rate $\dot{\delta}$

tyre lateral force $F_{y}$ is equivalent to vehicle yaw acceleration $\ddot{\psi}$

The Magic Formula for the vehicle's steering response can now be stated again as in equation (4), but with the terms now defined as:

$Y(X)$ steady state yaw acceleration $\ddot{\psi}$

$X$ steering rate $\dot{\delta}$

$B$ stiffness factor

$C$ shape factor

$D$ peak factor

$E$ curvature factor

$S_{h}$ horizontal shift

$S_{v}$ vertical shift

With the redefined parameters, the Magic Formula coefficients can be determined in the usual manner. The determination of the coefficients applied for the steering driver is now discussed.

\subsection{Determination of Coefficients}

The peak factor $D$ is determined by plotting the maximum yaw acceleration value $\ddot{\psi}$ against the vehicle speed $\dot{x}$. For this the graphs have to be interpolated. Quadratic curves were fitted through the vehicle's response curves, and the estimated peak values were used. The peak factor is defined as:

$D=a_{1} \dot{x}^{2}+a_{2} \dot{x}$

The peak factor curve was fitted through the estimated peak values, with emphasis on accurately capturing the data for vehicle speeds of 60 to $90 \mathrm{~km} / \mathrm{h}$. The resulting quadratic curve fit to the predicted peak values of the yaw acceleration is shown in Figure 8 . It is observed that the fit for the Magic Formula is poor for any speed below $60 \mathrm{~km} / \mathrm{h}$. This is 
attributed to the almost linear curve fit through the yaw acceleration vs. steering rate for speeds below $60 \mathrm{~km} / \mathrm{h}$, resulting in an unrealistically high prediction of the peak values. Thus, the insufficient fitting of the peak factor for speeds below $60 \mathrm{~km} / \mathrm{h}$ has little effect on the overall fit since the response will remain within the linear region at these speeds well beyond the steer rates which are humanly possible. The peak factor is however an important parameter in capturing the non-linear response at vehicle speeds over $60 \mathrm{~km} / \mathrm{h}$, hence the emphasis on accurately capturing the peak value at higher speeds.

In the original tyre model paper (Bakker, Pacejka and Linder, 1989), $B C D$ is defined as the cornering stiffness. Here it will be termed the 'yaw acceleration gain'. For the yaw acceleration gain the gradient at zero steering rate is plotted against vehicle speed as illustrated in Figure 9. The camber term $\gamma$ of the original paper will be ignored thus coefficient $a_{5}$ becomes zero. The yaw acceleration gain is fitted with the following function:

$$
B C D=a_{3} \sin \left(2 \arctan \left(\dot{x} / a_{4}\right)\right)\left(1-a_{5} \gamma\right)
$$

For the determination of the curvature $E$, quadratic curves were fitted through each of the curves in Figure 5. These approximations could then be differentiated twice to obtain the curvature for each. This curvature is plotted against vehicle speed $\dot{x}$ (Figure 10), and the straight line approximation:

$$
E=a_{6} \dot{x}+a_{7}
$$

is then fitted through the data points, in order to determine the coefficients $a_{6}$ and $a_{7}$. The straight line approximation fitted through the points is also shown in Figure 10.

The shape factor $C$, is determined by optimising the resulting Magic Formula fits to the measured data. This parameter is the only parameter that has to be adjusted in order to achieve better Magic Formula fits to the original data. It is defined in terms of the Magic Formula coefficient $a_{0}$ as follows:

$$
C=a_{0}
$$

The stiffness factor $B$ is determined by dividing $B C D$ by $C$ and $D$ :

$$
B=B C D / C D
$$

In the current research the horizontal and vertical shift of the curves were ignored allowing coefficients $a_{8}$ to $a_{13}$ to be assumed zero.

The Magic Formula fits to the original data are presented in Figure 11. It can be seen that all of the fits are very good. The insufficient fitting of the peak factor at speeds below 60 
$\mathrm{km} / \mathrm{h}$ as mentioned had no effect on the quality of the fit at those speeds. The gradient at all speeds is captured very well as to be expected from the fit of the yaw acceleration gain in Figure 8. The fit at 80 and $90 \mathrm{~km} / \mathrm{h}$ drops more at higher steer rates, however, the maximum relative error is still below $10 \%$.

With the Magic Formula coefficients being determined, the manipulation of the Magic Formula for the driver application is now discussed.

\section{Reformulated Magic Formula}

The steering driver requires, as output, the steering rate $\dot{\delta}$. For this reason the Magic Formula is reformulated to make it possible to have as inputs, vehicle velocity $\dot{x}$ and required vehicle yaw acceleration $\ddot{\psi}$, and as output required steering rate $\dot{\delta}$. However, due to the nature of the Magic Formula it is not possible to change the dependent variable of the formula. The arc tan function is therefore described by the pseudo arc tan function, suggested by Pacejka (2002), as:

$$
\text { pseudo } \arctan (x)=\frac{x(1+a|x|)}{1+2\left(b|x|+a x^{2}\right) / \pi}
$$

where $a=1.1$ and $b=1.6$. The Magic Formula can now be written as:

$$
\begin{aligned}
& F=B x-E\left(B x-\frac{B x(1+a|B x|)}{1+2\left(b|B x|+a(B x)^{2}\right) / \pi}\right) \\
& F=\tan \left(\frac{\arcsin (y / D)}{C}\right)
\end{aligned}
$$

A closed-form expression having $x$ as the dependent variable was obtained using MATLAB's Symbolic Math Toolbox (Matlab Symbolic Math Toolbox, 2008), and returns an exceptionally long equation, of three terms, not presented here due to its shear size. This resulting equation is coded into the Simulink model consisting of the MSC.ADAMS model and the steering controller.

\section{Implementation of Results}

In order to validate the performance of the proposed methodology, the Magic Formula driver was implemented in the vehicle simulation model. The driver model is interfaced with the MSC.ADAMS simulation via a MSC.ADAMS/Simulink co-simulation. The vehicle model's differential equations are solved using MSC.ADAMS. The simulation model supplies the driver model, which is implemented in Simulink, at each time step with the $x$ position of the vehicle's cg, vehicle speed, yaw rate as well as yaw angle. The desired yaw angle is obtained from the $x$ position of the vehicle's cg and the desired path, which is also modelled in Simulink. The driver model then solves for the required steer 
rate input and returns the integration thereof to the simulation. This interface is graphically displayed in Figure 12.

The vehicle was simulated performing the ISO3888-1 (International Organisation for Standardisation, 2004) double lane change manoeuvre. The excellent comparison with measured results is presented in Figure 13, for kingpin angle, yaw velocity, left rear (lr) spring displacement and left front (lf) lateral acceleration. It is important to note that the double lane change is simulated at a constant speed while the measured results (see Figure 2) show that the driver decreased speed during the manoeuvre, explaining the discrepancies towards the end of the double lane change.

Comparison of the kingpin steering angle produced by the driver model and that applied by the human driver during actual tests (Figure 13) indicates that the driver model closely follows human driver behaviour. It should also be noted that significant differences exist for the human driver behaviour during different test runs.

The driver model was then analysed for changing the vehicle's suspension system from stiff to soft, for various speeds. Presented in Figure 14 is the driver model's ability to keep the vehicle at the desired yaw angle (Genta, 1997) over time. From the results it can be seen that a varying preview time with vehicle speed, would be beneficial, however, it is felt that for this preliminary research the constant 0.5 seconds preview time is sufficient. Also it is evident that the softer suspension system, at $70 \mathrm{~km} / \mathrm{h}$ vehicle speed, is slightly less stable, as seen by the oscillatory nature at the end of the double lane change manoeuvre.

The results show that the driver model provides a well controlled steering input. Also there is a lack of high frequency oscillation typically associated with single point preview driver models, when applied to highly non-linear vehicle models like SUV's, which are being operated close to their limits in the double lane change manoeuvre.

Another non-linear driver model implemented was that of Freund and Mayr (1997). This driver model includes a dynamic vehicle model, inclusion of the non-linear tyre dynamics, speed dependent steer angle saturation function. The driver model also implements a path filter which incorporates the path angle and the rate of path angle change in the preview point. Aspects of this driver model are implemented in the commercial software veDYNA (Plöchl and Edelmann, 2007 and Irmscher and Ehmann, 2004). The driver model has one tuning parameter which was tuned to give the best performance at $60 \mathrm{~km} / \mathrm{h}$. Presented in Figure 15 is the driver model's ability to keep the vehicle at the desired yaw angle over time. In comparison to the proposed driver model, Freund's model provides stable but poorer performance over the given manoeuvre.

The proposed driver model was successfully used in the optimisation of a vehicle suspension system by Thoresson et al. (2009a and 2009b), where the requirement for a robust driver model is essential. The driver model allowed suspension parameters to be modified without requiring any modification to the driver model while still maintaining excellent path following ability. 
The fact that the driver model parameters, obtained from the baseline suspension characteristics, also work well for the other suspension characteristics, indicates that the driver model is robust, but also that vehicle yaw response is strongly dependant on the lateral tyre properties.

\section{Conclusions}

It has been shown that the Magic Formula, traditionally used for describing tyre characteristics, can be fitted to the vehicle's steering response, in the form of yaw acceleration vs. steering rate, for different vehicle speeds.

A robust single point steering driver model has been successfully implemented on a highly non-linear vehicle model. The success of the single point steering driver can be attributed to the non-linear gain factor, modelled using the Magic Formula, that changes in value with vehicle speed and required yaw acceleration.

Future work could entail an investigation into determining the driver model parameters directly from the lateral tyre properties instead of using the expensive simulation. A further aspect that could be considered is determining the value of varying preview time with vehicle speed.

\section{References}

Bakker, E., Pacejka, H.B., Linder, L. (1989) 'A New Tire Model with an Application in Vehicle Dynamics Studies', SAE 890087.

CarSim (2011). Mechanical Simulation Corporation. Obtained through the Internet: http://www.carsim.com, [accessed 08/02/2011].

Freund, E. and Mayr, R. (1997) 'Nonlinear Path Control in Automated Vehicle Guidance', IEEE Transactions on Robotics and Automation, Volume 13/1(1997), pp. 4960 .

Genta, G. (1997), Motor Vehicle Dynamics, Modelling and Simulation. Series on Advances in Mathematics for Applied Sciences: Volume 43. World Scientific, New Jersey, USA.

Gordon,T.J., Best, M.C., Dixon, P.J. (2002) 'An Automated Driver Based on Convergent Vector Fields'. Proceedings of the Institute of Mechanical Engineers, Part D: Journal of Automotive Engineering, 216 Special Issue, pp. 36-56.

Hugemann, W. and Nickel, M. (2002) ,Longitudinal and Lateral Accelerations in Normal Day Driving'. Ingenieurburo Morawski and Hugemann. Obtained through the Internet: http://www.unfallrekonstruktion.de/pdf/itai_2003 english.pdf, [accessed 08/02/2011]. 
International Organisation for Standardisation (2004) Passenger cars - Test track for a severe lane-change manoeuvre - Part 1: Double lane-change ISO 3888-1, 06 October 2004.

Irmscher, M. and Ehmann, M. (2004) 'Driver Classification Using ve-DYNA Advanced Driver', SAE 2004-01-0451.

Matlab Symbolic Math Toolbox (2008), Obtained through the Internet:

http://www.mathworks.com/products/symbolic/, [accessed 09/04/2008].

Pacejka, H.B. (2002) Tyre and Vehicle Dynamics, Society of Automotive Engineers Warrendale, USA.

Plöchl, M. and Edelmann, J. (2007) 'Driver models in automobile dynamics application', Vehicle System Dynamics, 45:7, pp. 699-741.

Prokop, G. (2001) 'Modelling Human Vehicle Driving by Model Predictive Online Optimisation', Vehicle System Dynamics, Volume 35/1, pp. 19-53.

Qinchao, Z., Xuncheng, W., Fang, L. (2011) 'The Overview of Active Front Steering System and The Principle of Changeable Transmission Ratio', 2011 Third International Conference on Measuring Technology and Mechatronics Automation. pp. 894-897.

Reymond, G., Kemeny, A., Dorulez, J., Berthoz, A. (2001) 'Role of Lateral Acceleration in Curve Driving: Driver Model and Experiments on a Real Vehicle and a Driving Simulator', Human Factors: The Journal of the Human Factors and Ergonomics Society, 2001 43: 483.

Sharp, R.S., Casanova, D., Symonds, P. (2000) 'A Mathematical Model for Driver Steering Control, with Design, Tuning and Performance Results', Vehicle System Dynamics, Vol 33, pp. 289-326.

Snider, J.M. (2009) 'Automatic Steering Methods for Autonomous Automobile Path Tracking', Technical Report CMU-RI-TR-09-08, Carnegie Mellon University Robotics Institute. Obtained through the Internet:

http://www.ri.cmu.edu/pub files/2009/2/Automatic Steering Methods for_Autonomous _Automobile_Path_Tracking.pdf, [accessed 08/02/2011].

Tewari, A. (2002) Modern Control Design. Wiley.

Thoresson, M.J., Uys, P.E., Els, P.S., Snyman, J.A. (2009b) 'Efficient optimisation of a vehicle suspension system, using a gradient-based approximation method, Part 1: Mathematical modelling', Mathematical and Computer Modelling, 50 (2009), pp. 14211436. 
Thoresson, M.J., Uys, P.E., Els, P.S., Snyman, J.A. (2009a) 'Efficient optimisation of a vehicle suspension system, using a gradient-based approximation method, Part 2: Optimisation results', Mathematical and Computer Modelling, 50 (2009) pp. 1437-1447.

Thrun, S., Montemerlo, M., Dahlkamp, H., Stavens, D., Aron, A., Diebel, J., Fong, P., Gale, J., Halpenny, M., Hoffmann, G., Lau, K., Oakley, C., Palatucci, M., Pratt, V., Stang, P., Strohband, S., Dupont, C., Jendrossek, L.E., Koelen, C., Markey, C., Rummel, C., van Niekerk, J., Jensen, E., Alessandrini, P., Bradski, G., Davies, B., Ettinger, S., Kaehler, A., Nefian, A., Mahoney, P. (2006) 'Stanley: The Robot That Won the DARPA Grand Challenge', Journal of Field Robotics, 23(9), pp. 661-692.

Urmson, C., Anhalt, J., Bagnell D., Baker, C., Bittner, R., Clark, M.N., Dolan, J., Duggins, D., Galatali, T., Geyer, C., Gittleman, M., Harbaugh, S., Herbert, M., Howard, T.M., Kilski, S., Kelly, A., Likhachev, M., McNaughton, M., Miller, N., Peterson, K., Pilnick, B., Rajkumar, R., Rybski, P., Salesky, B., Seo, Y.W., Singh, S., Snider, J., Stentz, A., Whittaker, W., Wolkowicki, Z., Ziglar, J., Hong, B., Brown, T., Demitrish, D., Litkouhi, B., Nickolaou, J., Sadekar, V., Zhang, W., Struble, J., Taylor, M., Darms, M., Ferguson, D. (2008) 'Autonomous Driving in Urban Environments: Boss and the Urban Challenge', Journal of Field Robotics, 25(8), pp. 425-466.

Uys, P.E., Els, P.S., Thoresson, M.J., Voigt, K.G., Combrink, W.C. (2005) 'Experimental determination of moments of inertia for an off-road vehicle in a regular engineering laboratory', International Journal of Mechanical Engineering Education, Volume 34/4, pp. 291-314. 


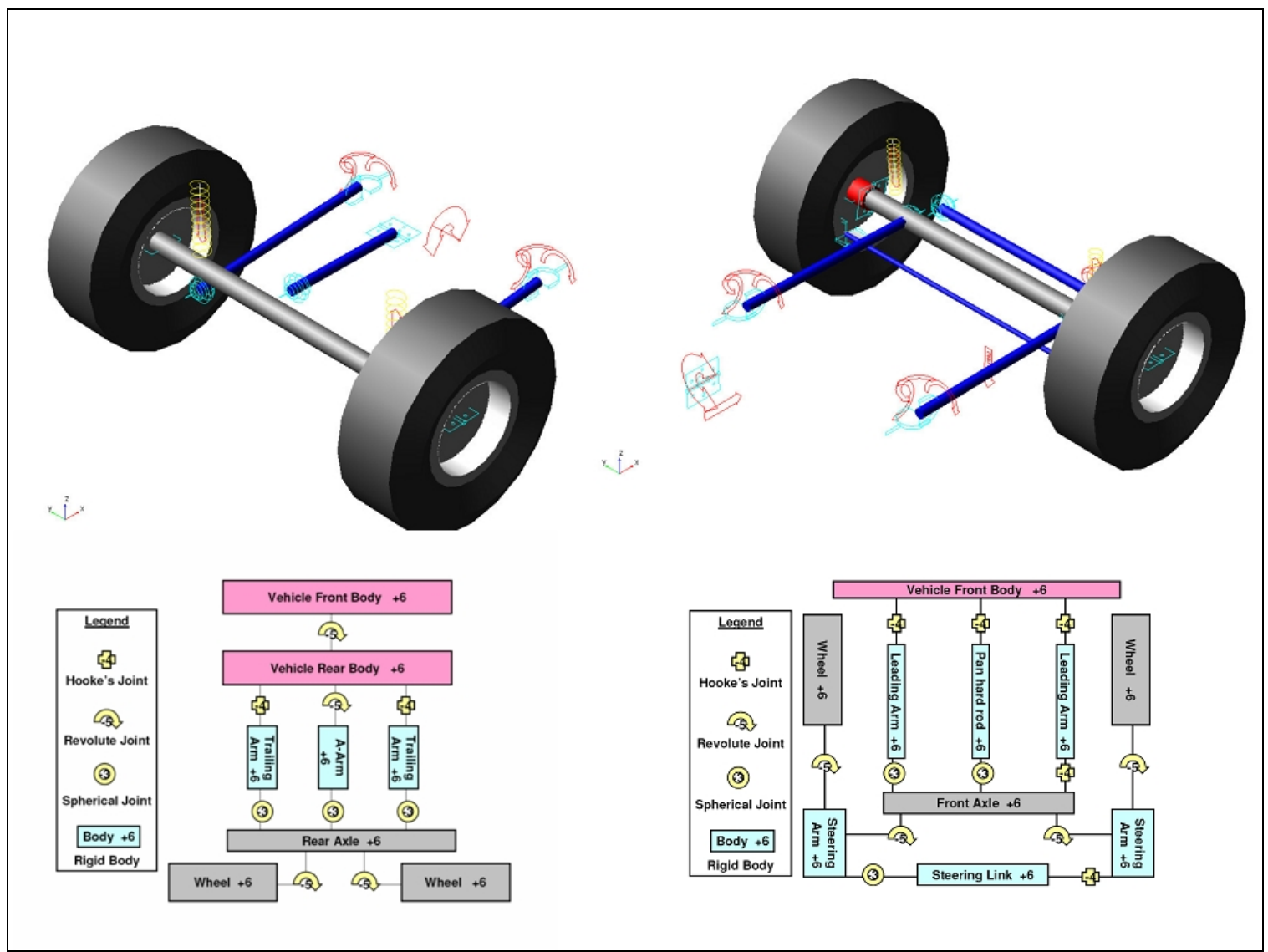

Figure 1. Model of the full vehicle in MSC.ADAMS 

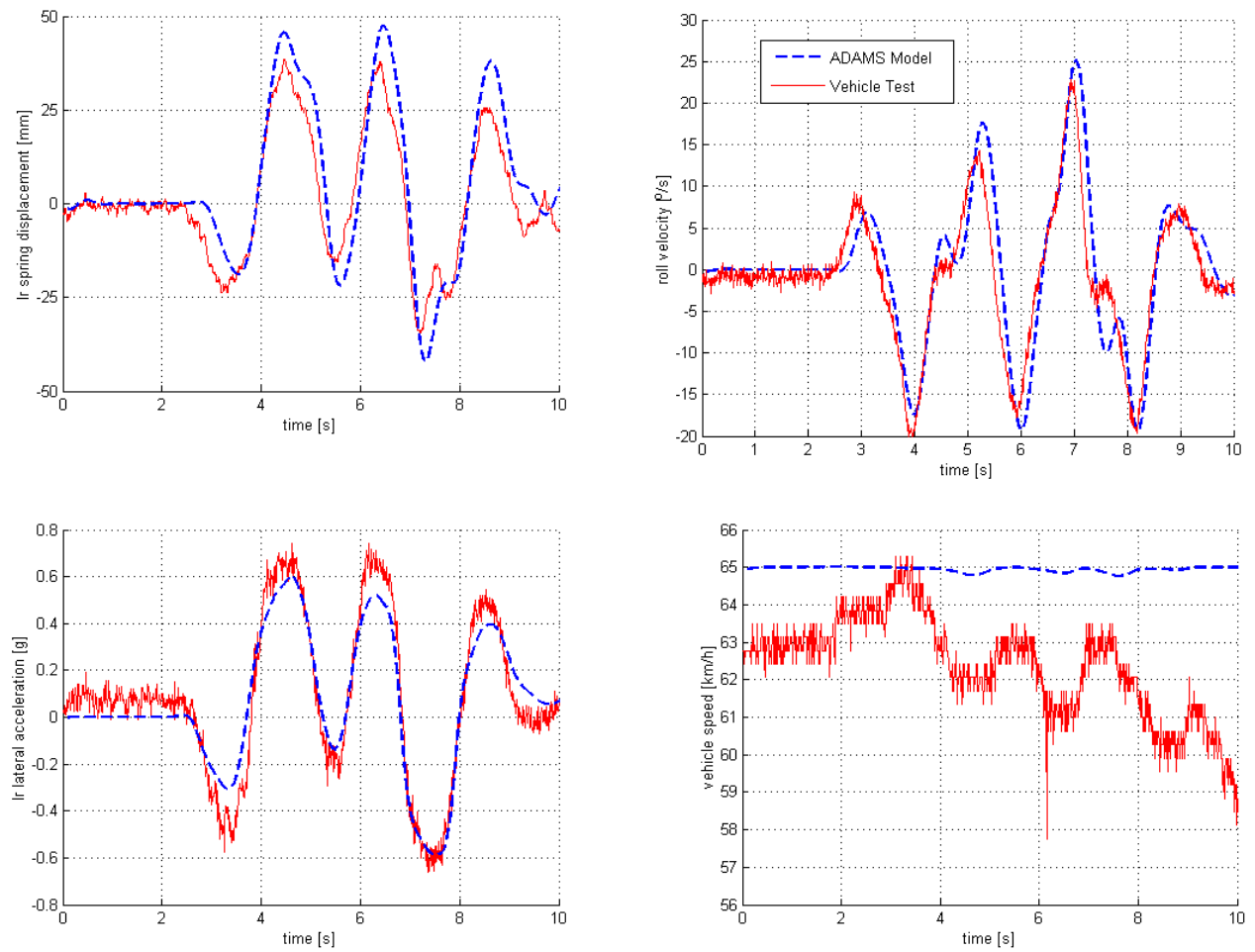

Figure 2. Validation of MSC.ADAMS model's handling dynamics. Double lane change at an entry speed of $65 \mathrm{~km} / \mathrm{h}$. Steering input measured during tests used (lr refers to left rear). 

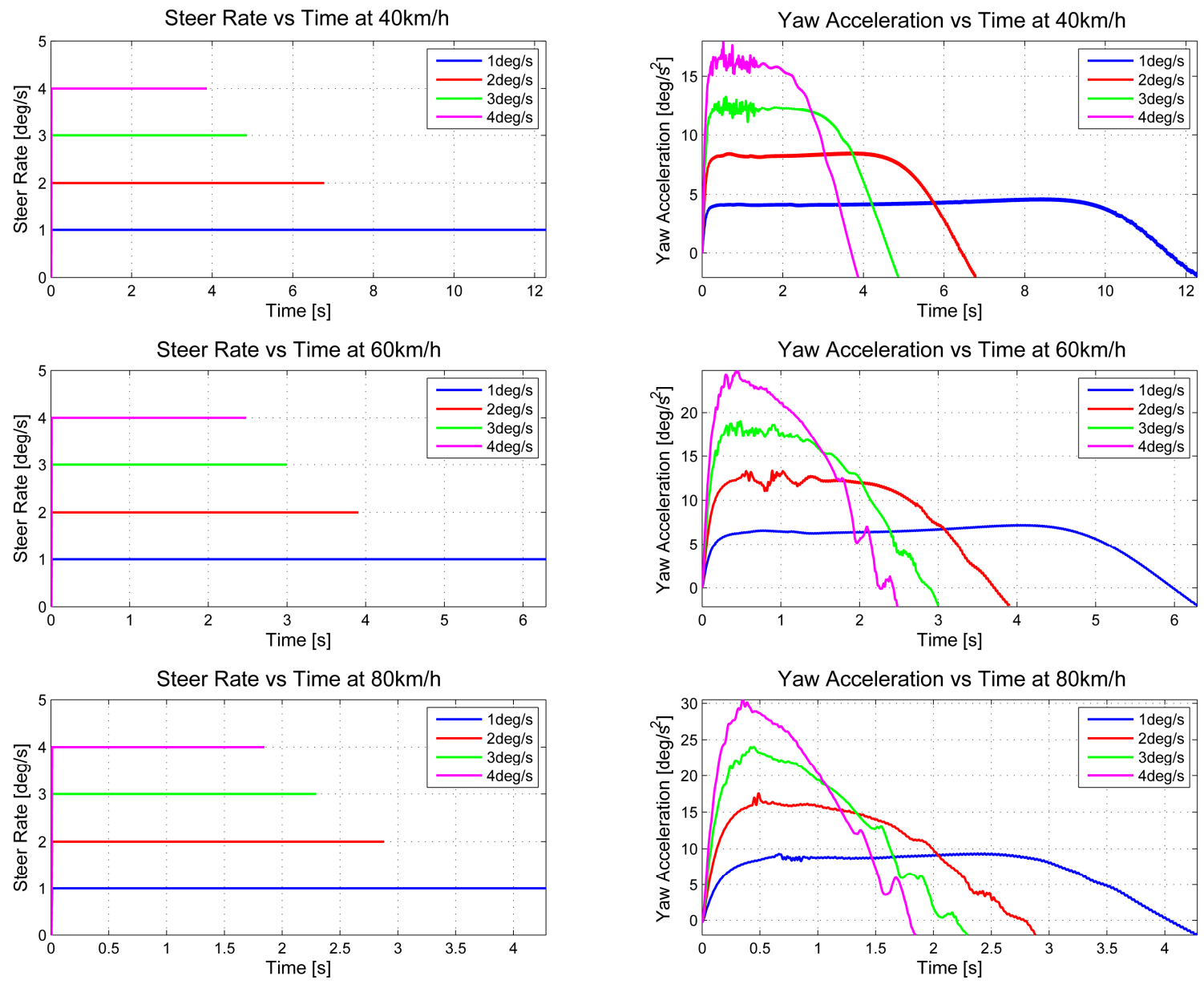

Figure 3. Yaw acceleration response to front wheel steer rate at various vehicle speeds. 

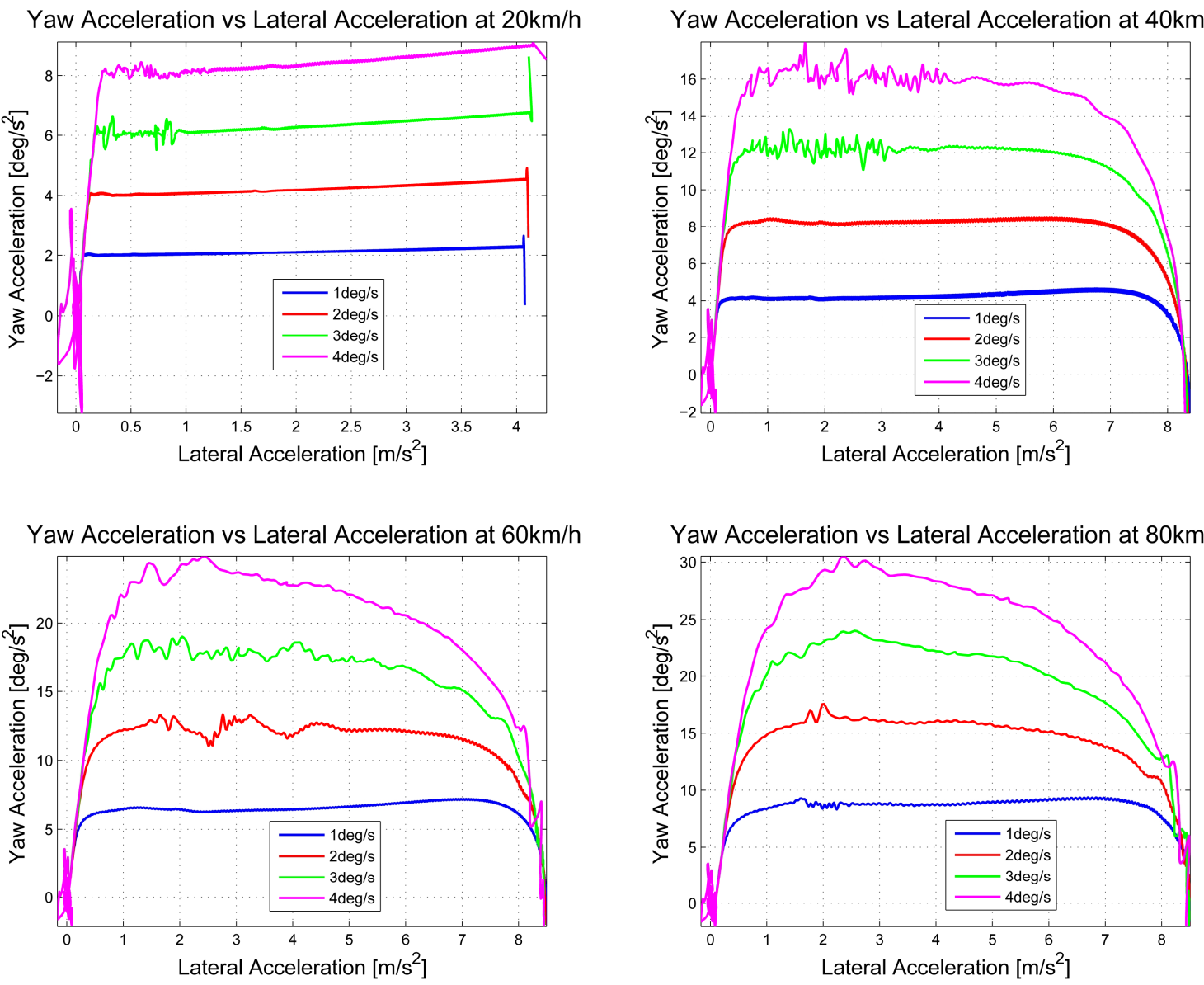

Figure 4. Yaw acceleration vs. lateral acceleration for various front wheel steer rates at various vehicle speeds. 


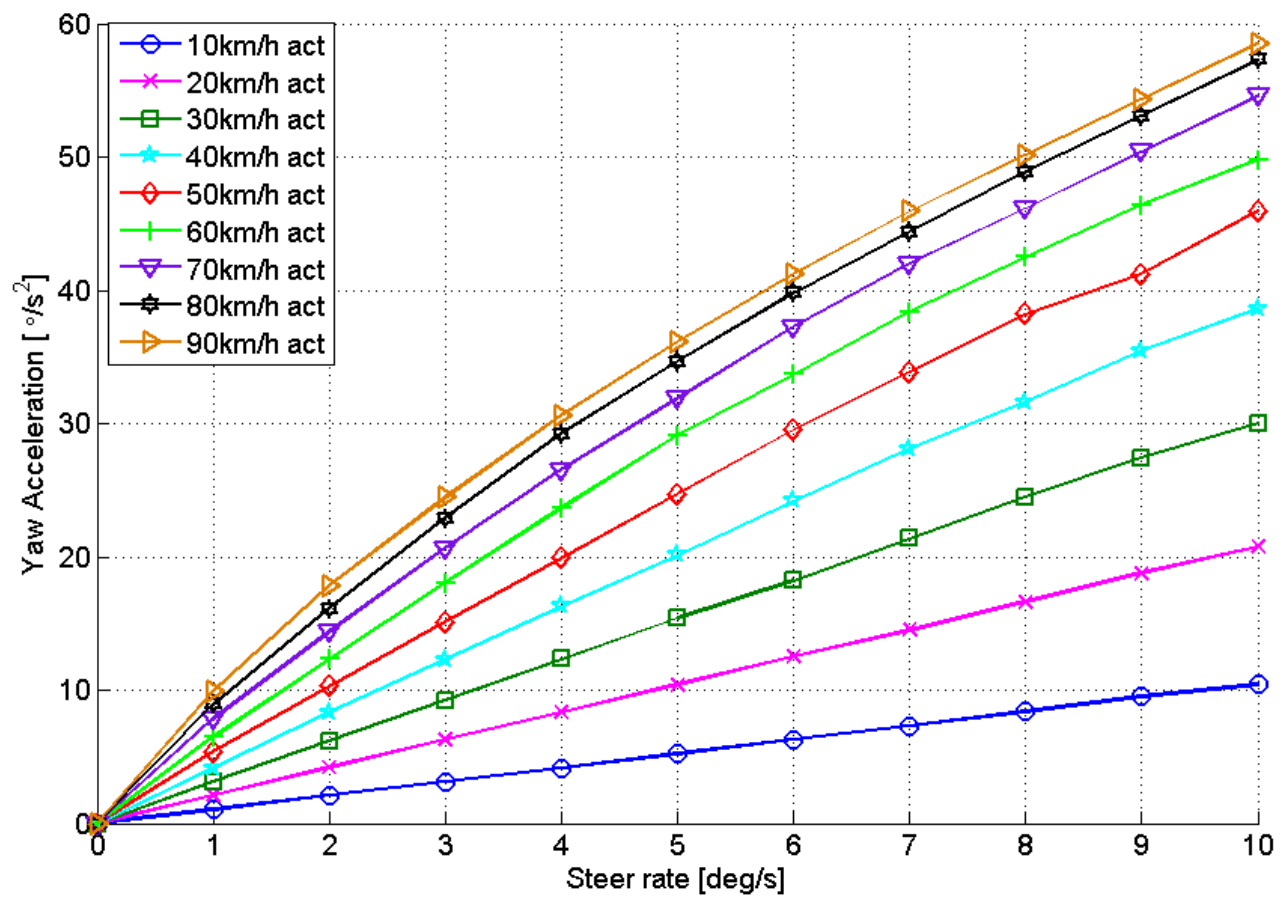

Figure 5. Vehicle yaw acceleration response to different steering rates 


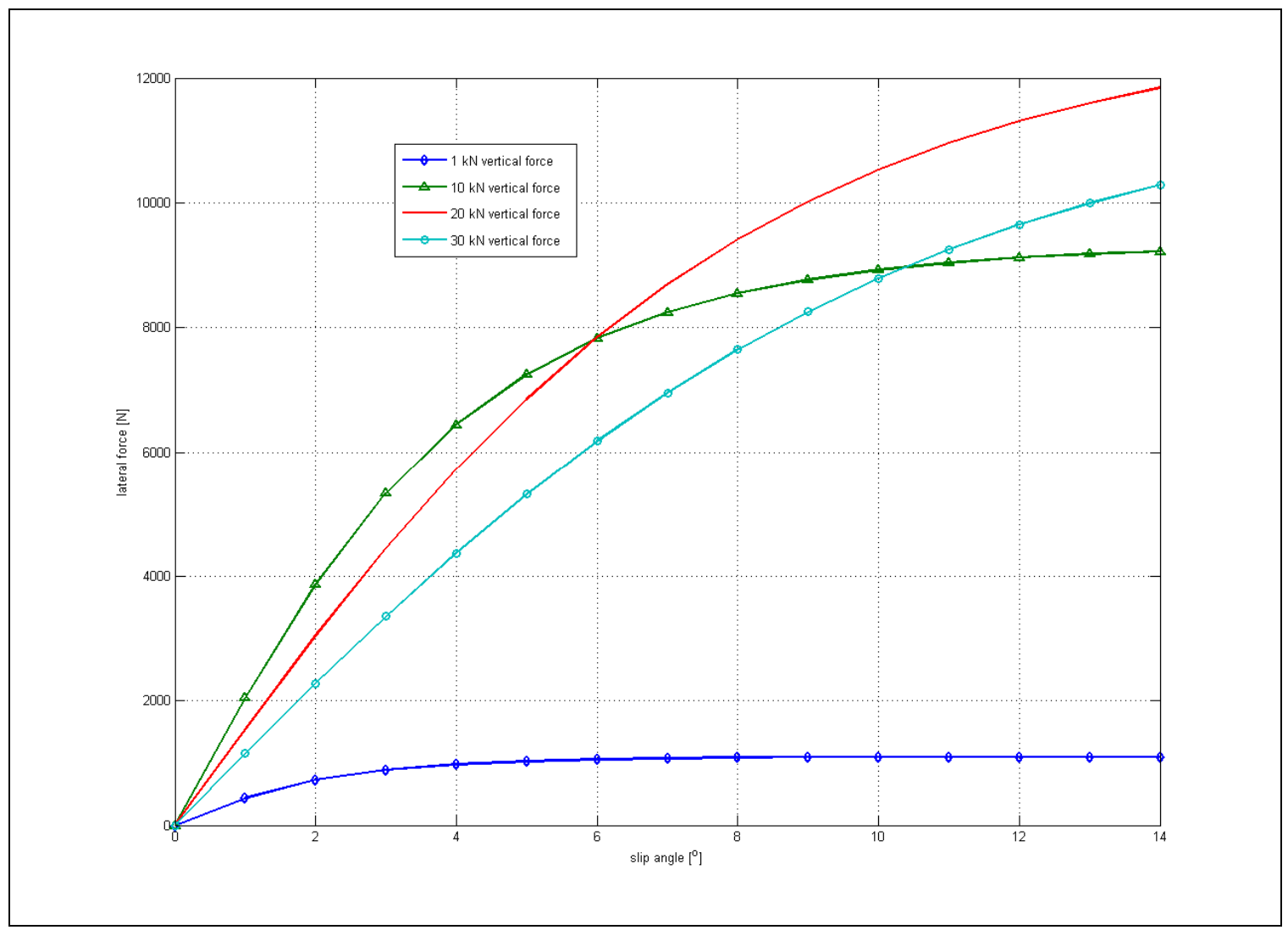

Figure 6. Tyre lateral force vs. slip angle characteristics for different vertical loads 


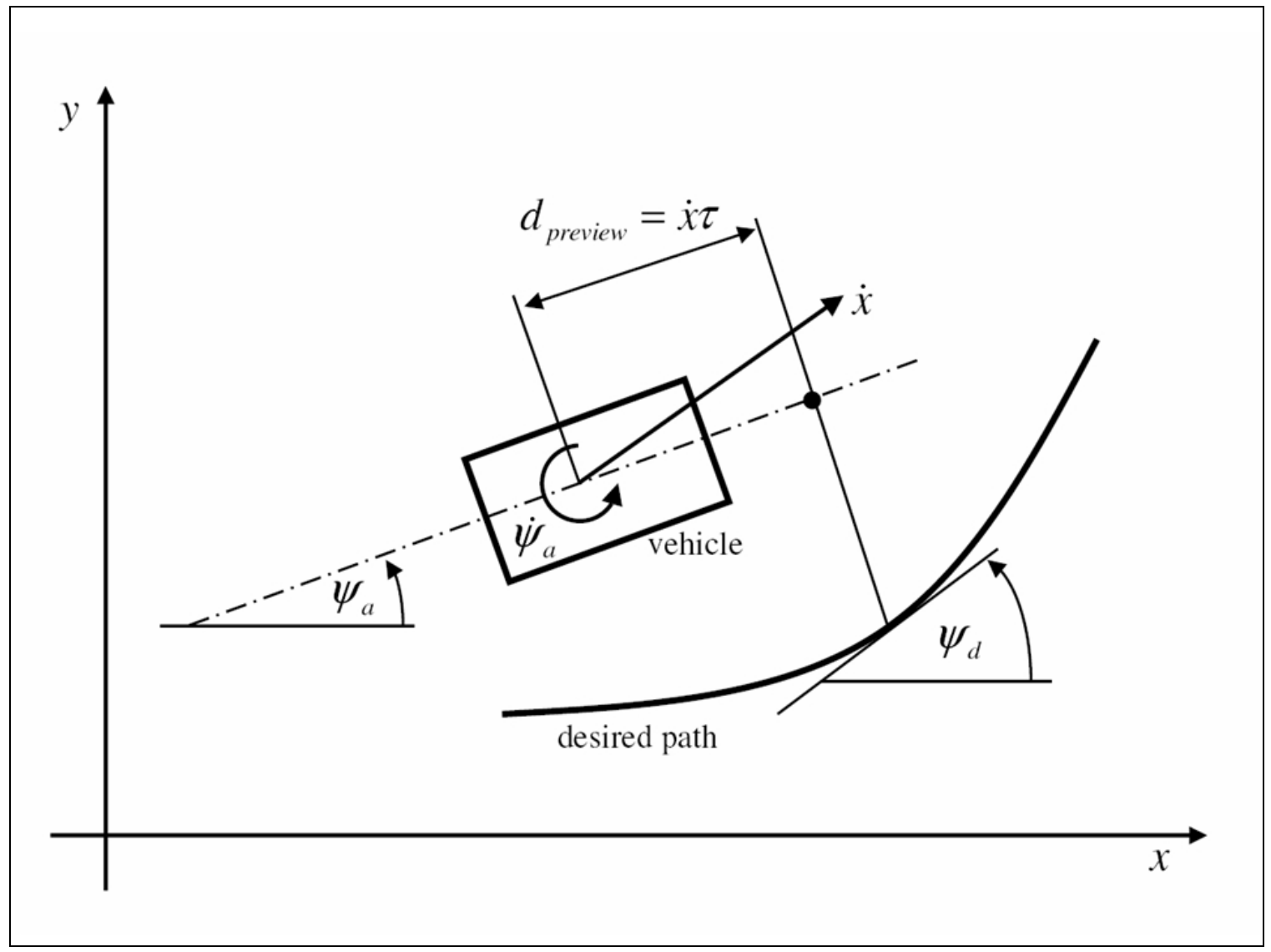

Figure 7. Definition of driver model parameters 


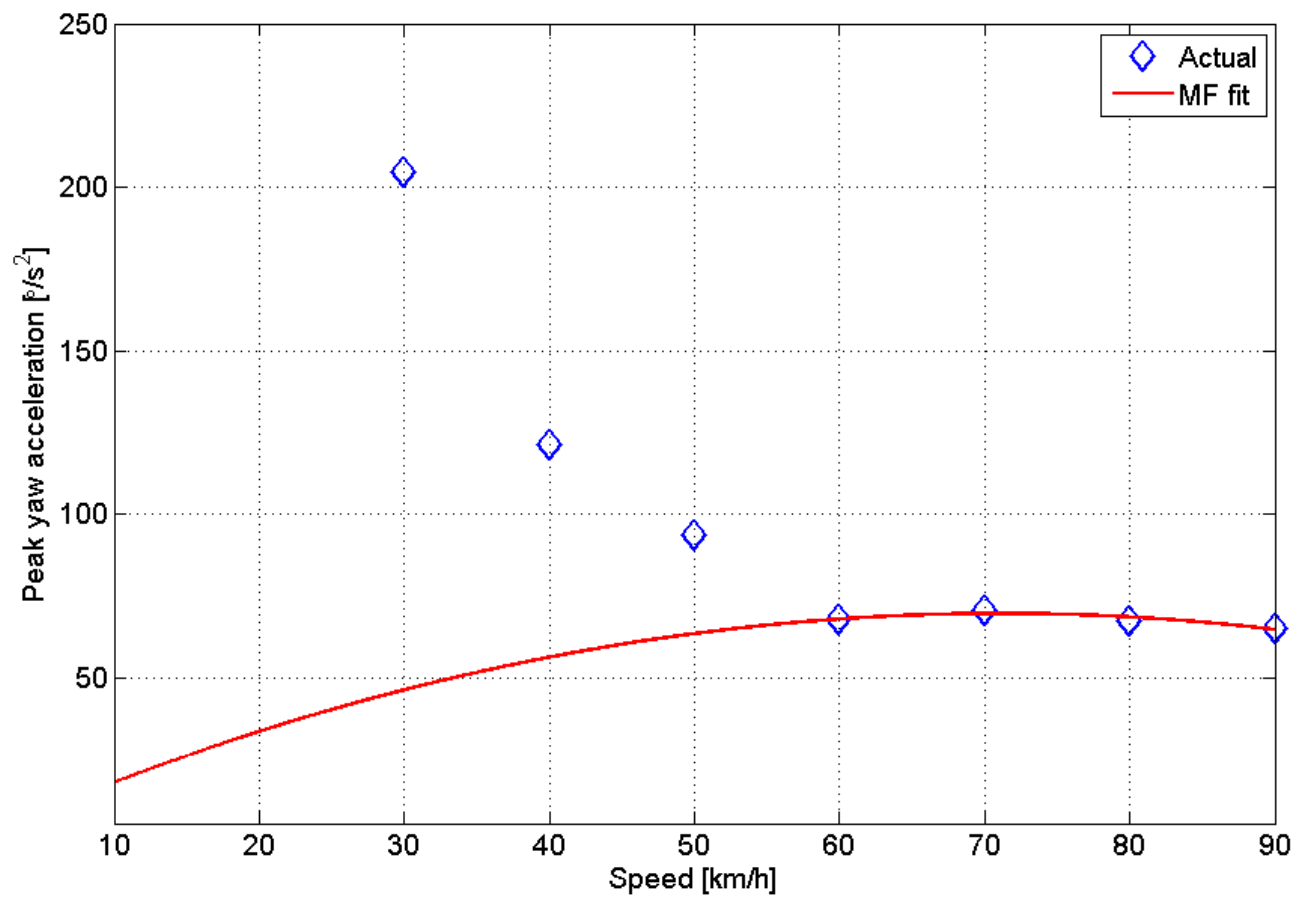

Figure 8. Magic Formula coefficient quadratic fit through equivalent peak values 


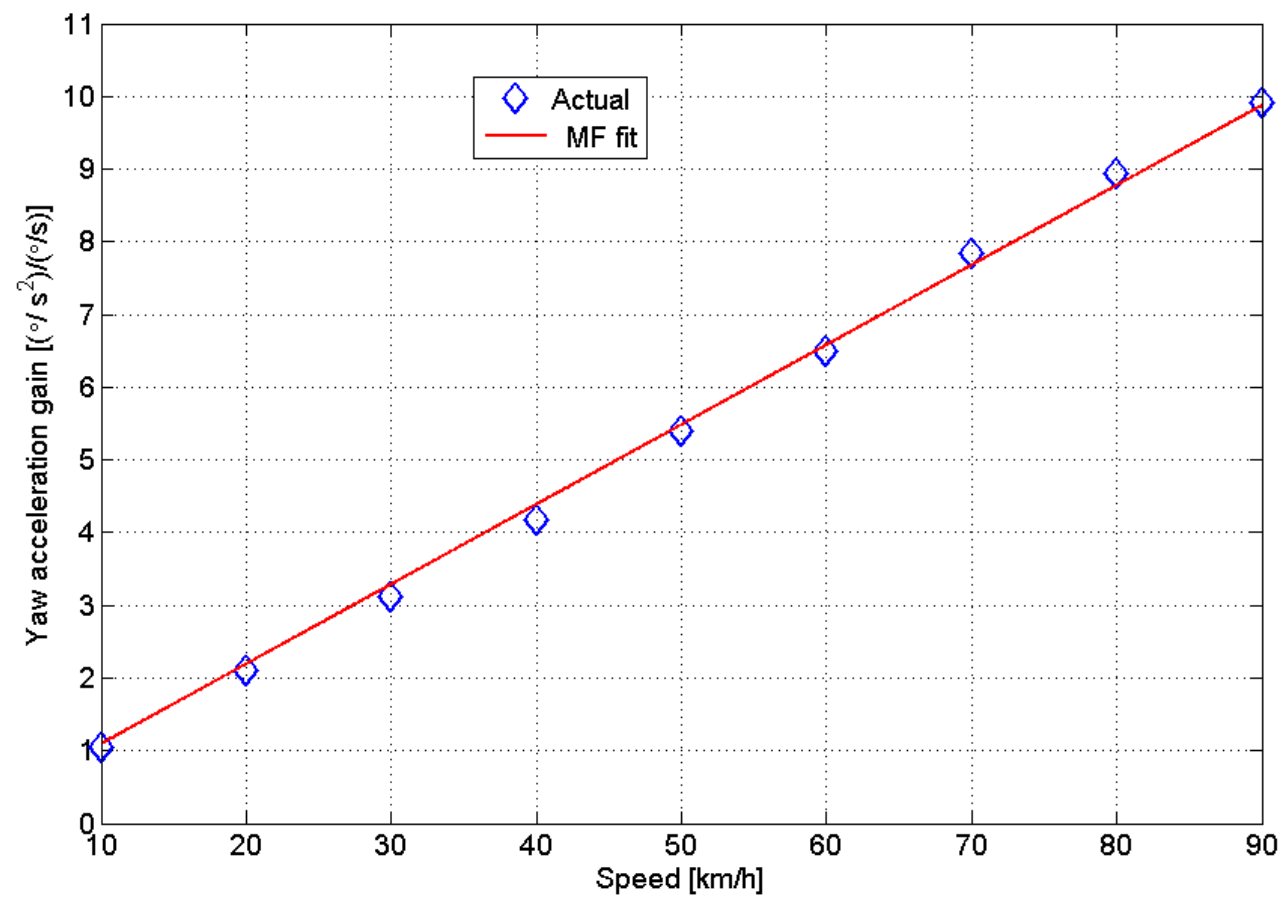

Figure 9. Magic Formula fit of yaw acceleration gain through the actual data 


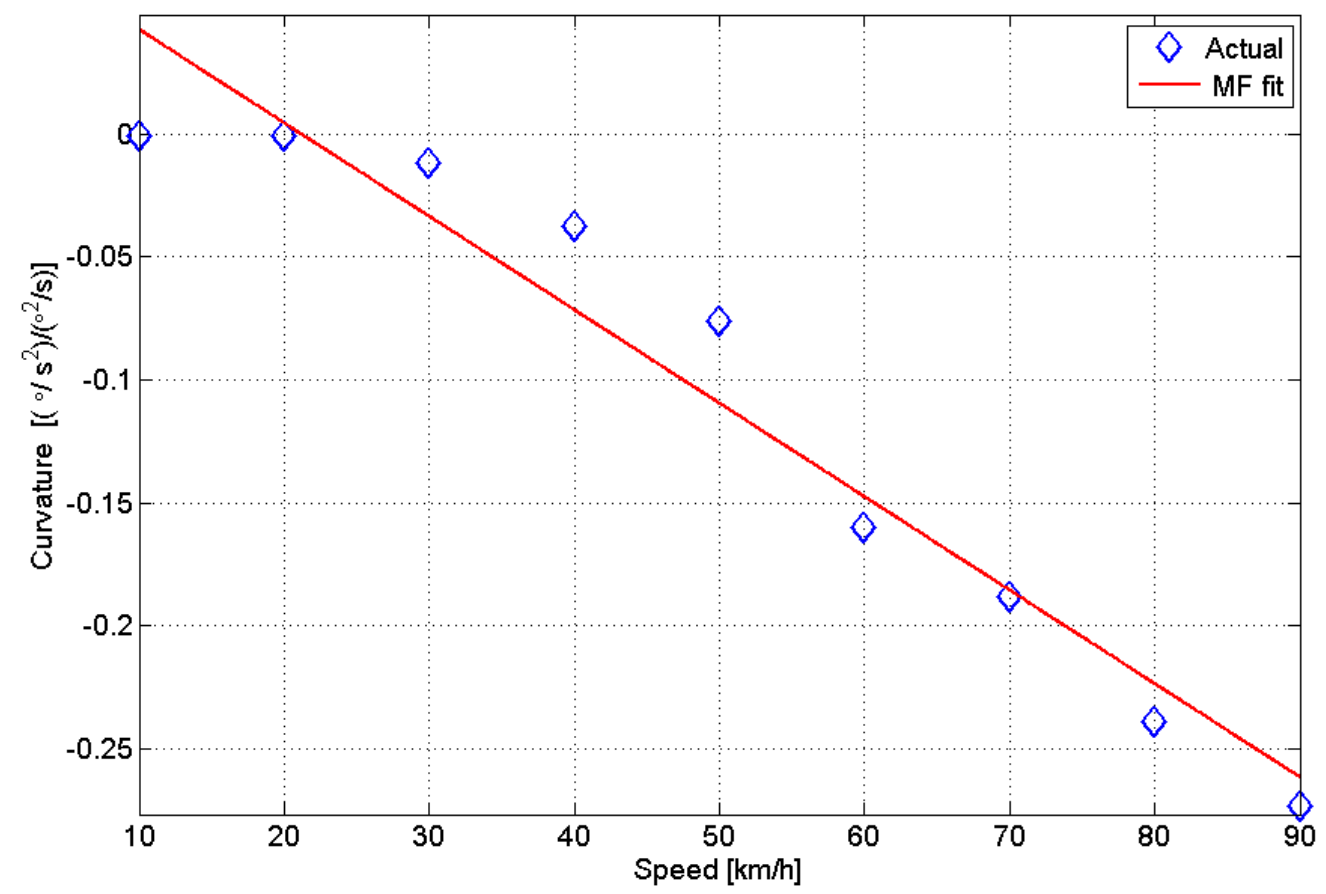

Figure 10. Determination of curvature coefficients 


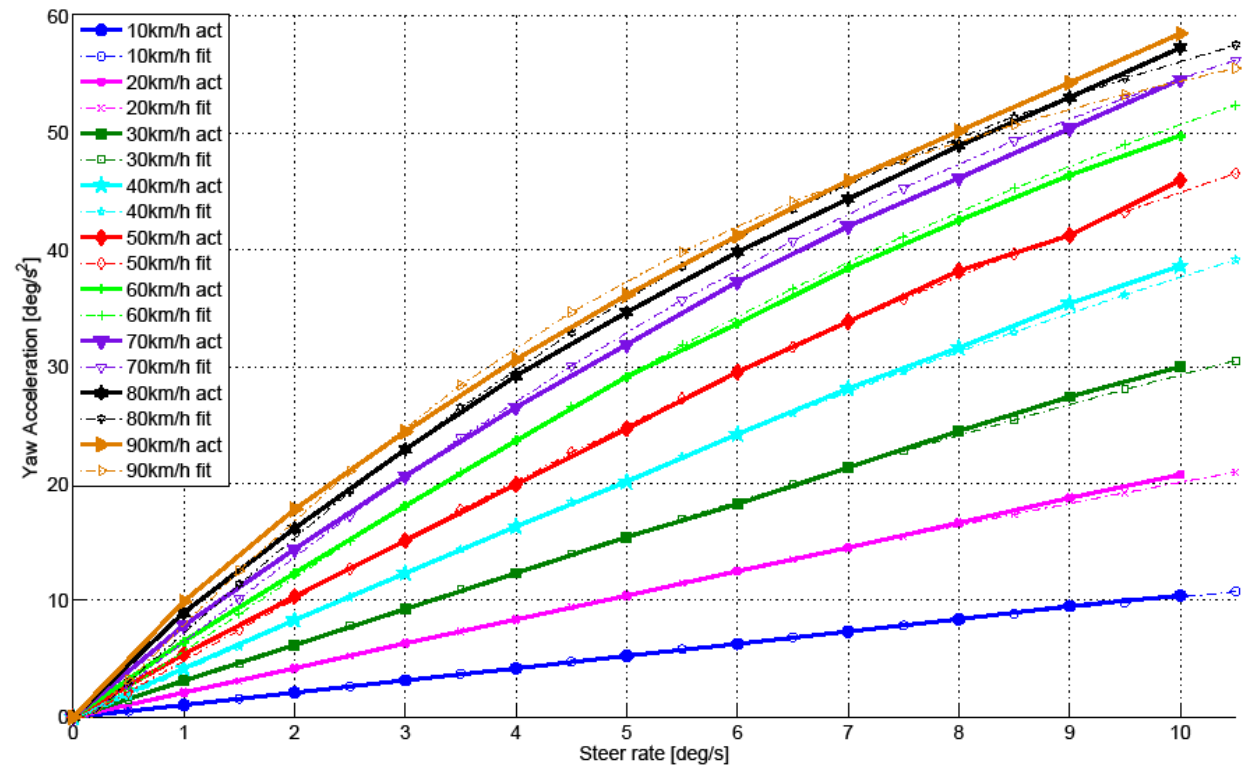

Figure 11. Magic Formula fits to original vehicle steering behaviour 


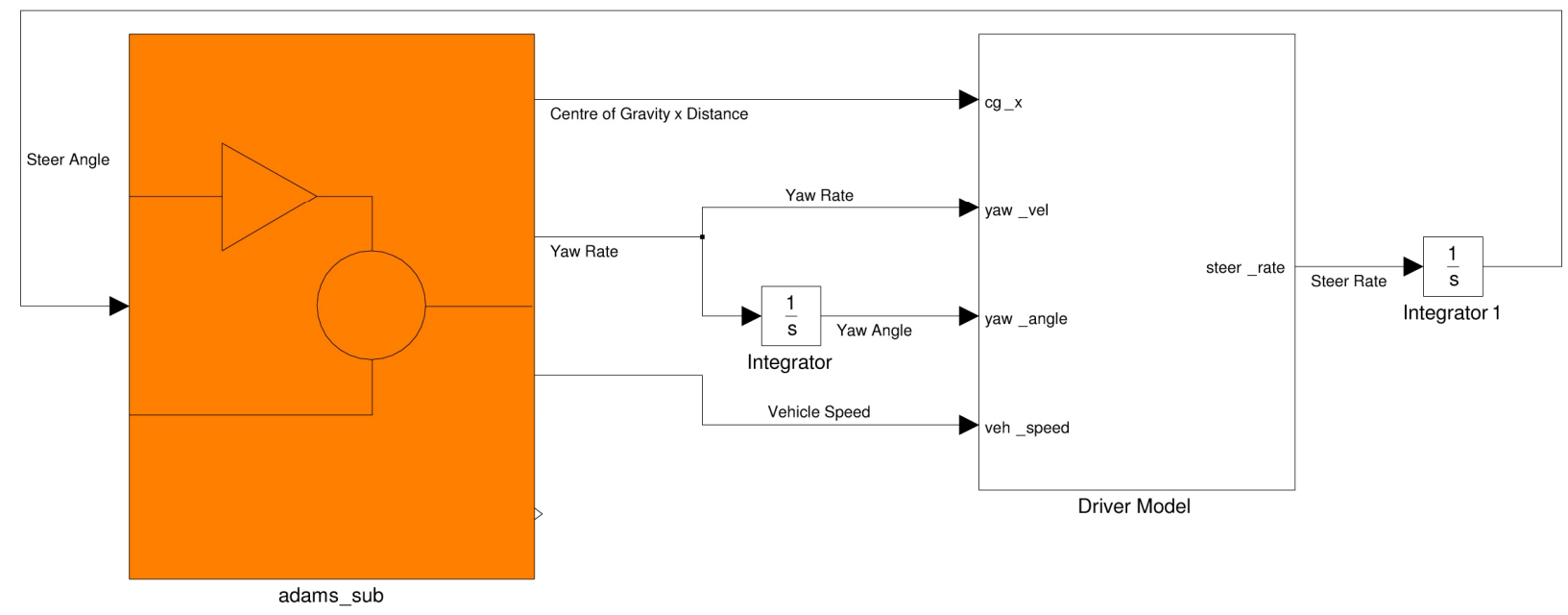

Figure 12. ADAMS simulation and driver model interface 

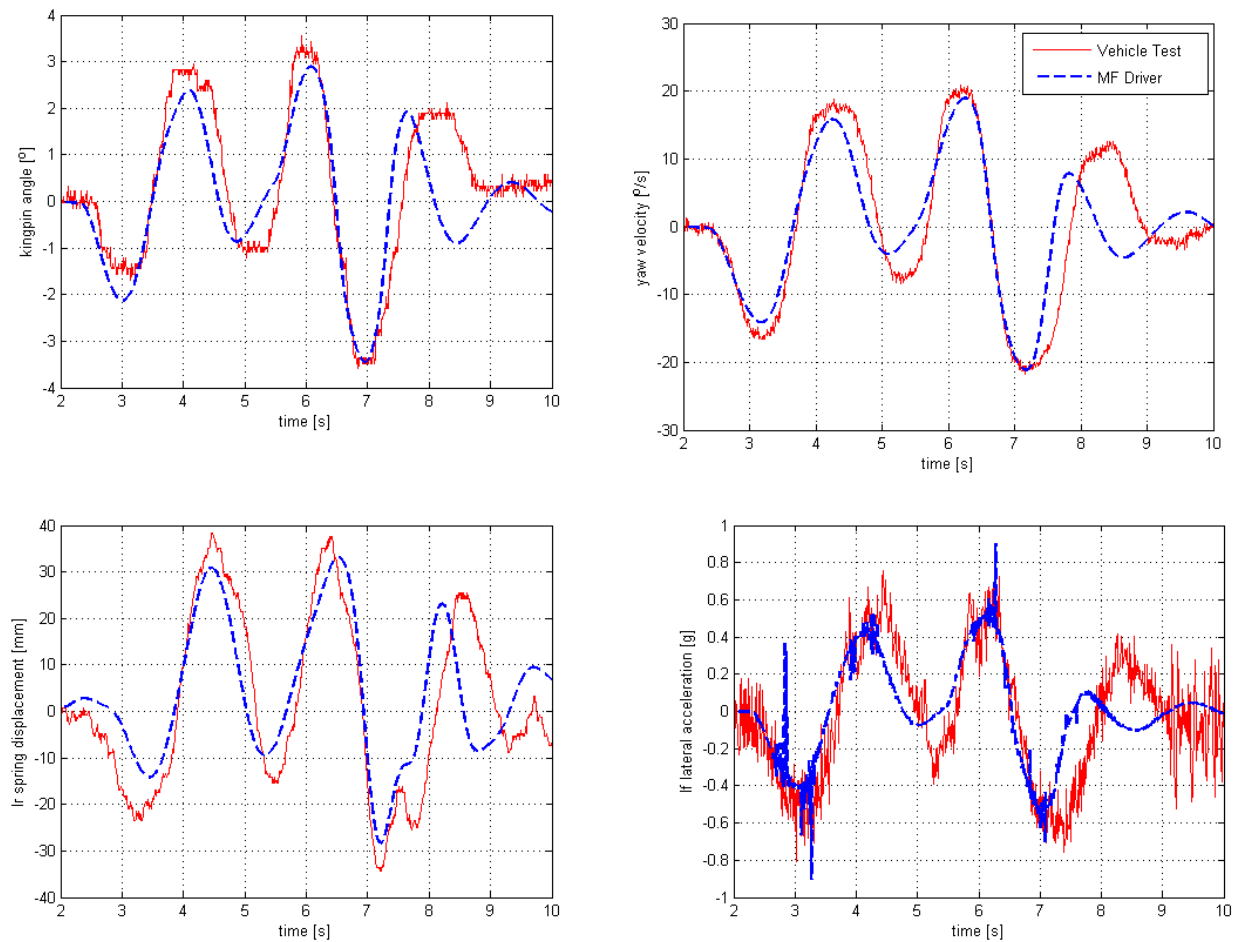

Figure 13. Correlation of Magic Formula driver model to vehicle test at an entry speed of $63 \mathrm{~km} / \mathrm{h}$ 


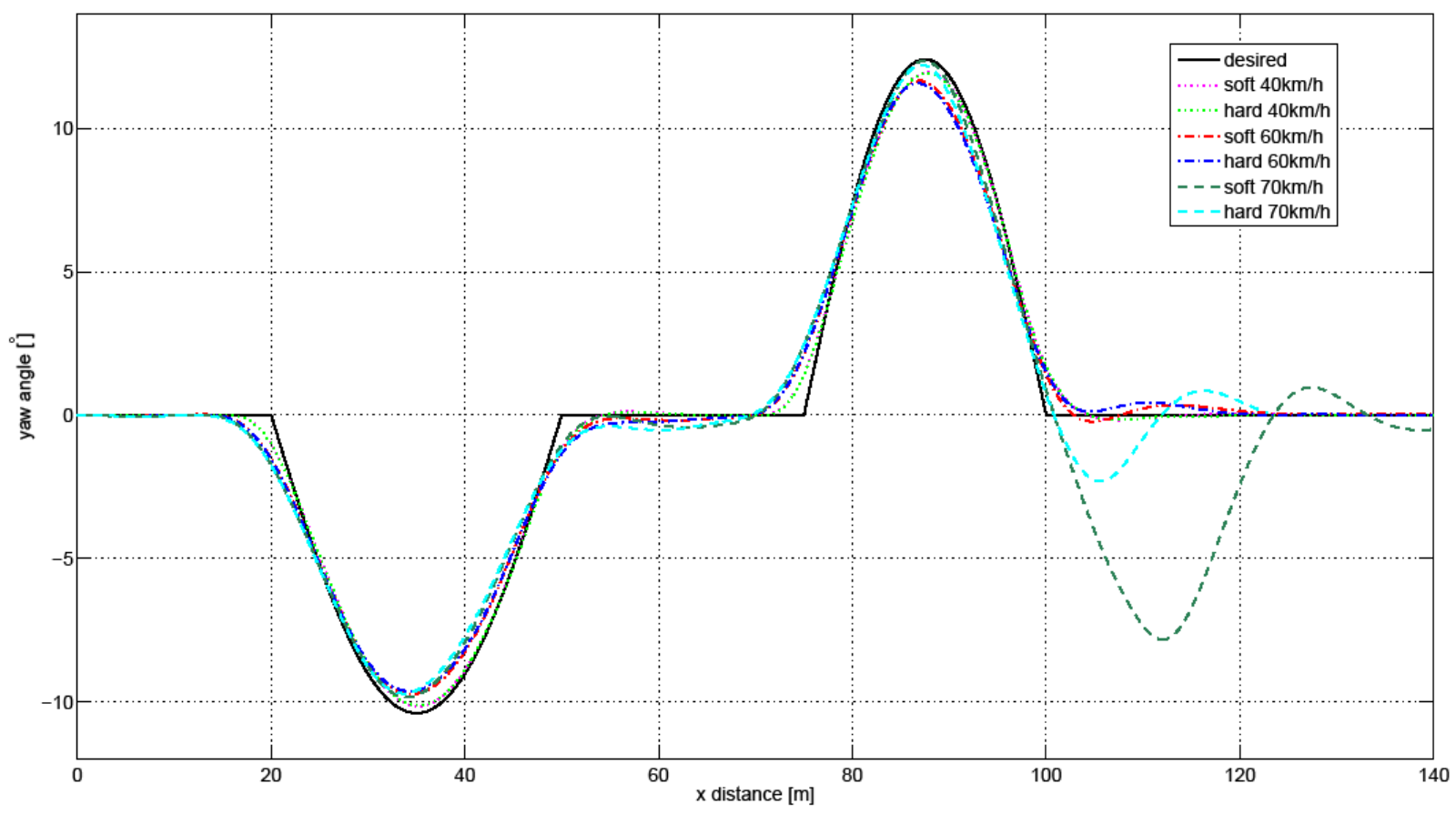

Figure 14. Comparison of different suspension settings and vehicle speeds, for the double lane change manoeuvre with proposed driver model, where the desired is as proposed by Genta (1997) 


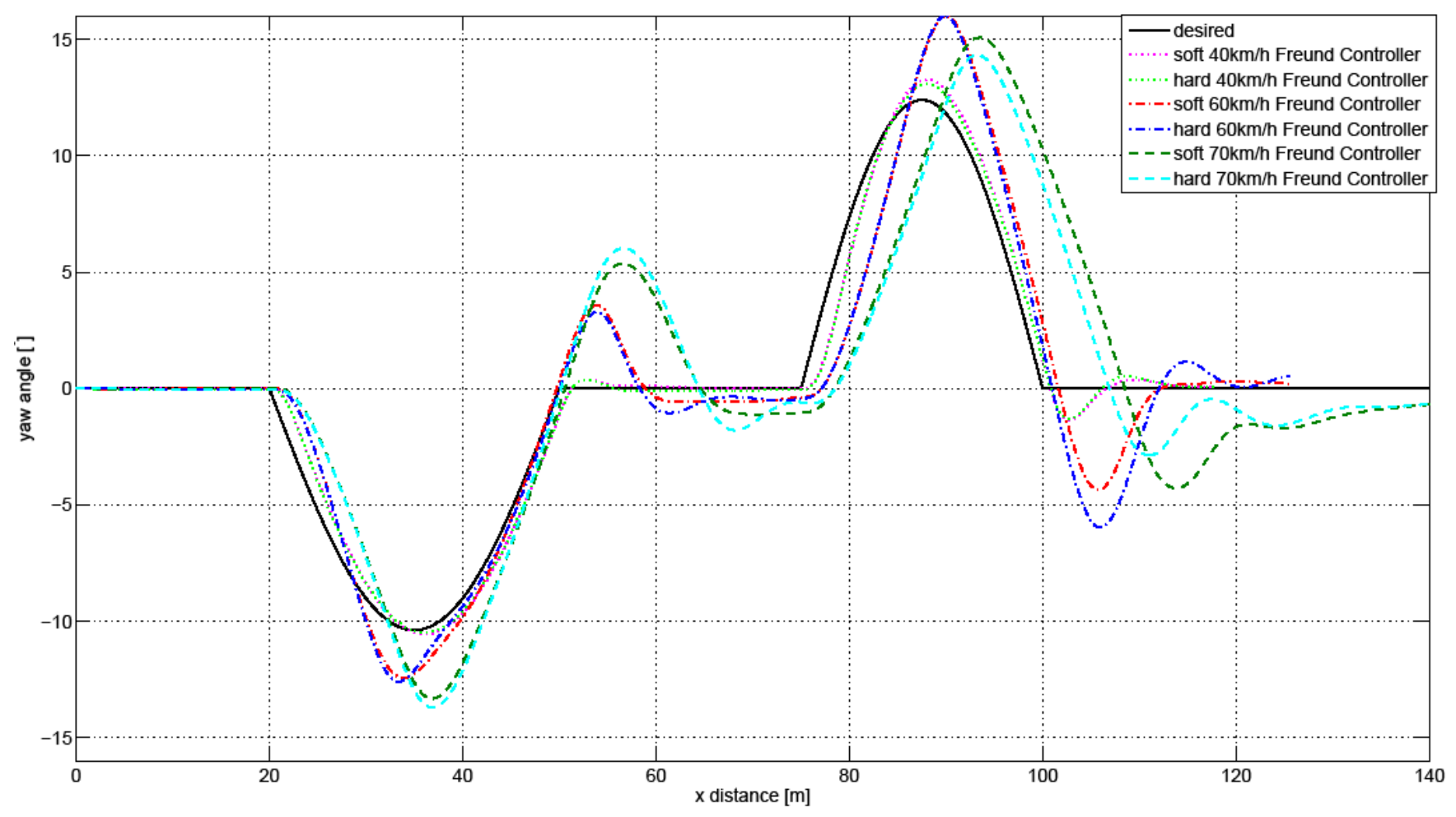

Figure 15. Comparison of different suspension settings and vehicle speeds, for the double lane change manoeuvre with driver model by Freund and Mayer (1997), where the desired is as proposed by Genta (1997) 